\title{
Diagnostic ileoscopy assisting in the diagnosis of Whipple's disease
}

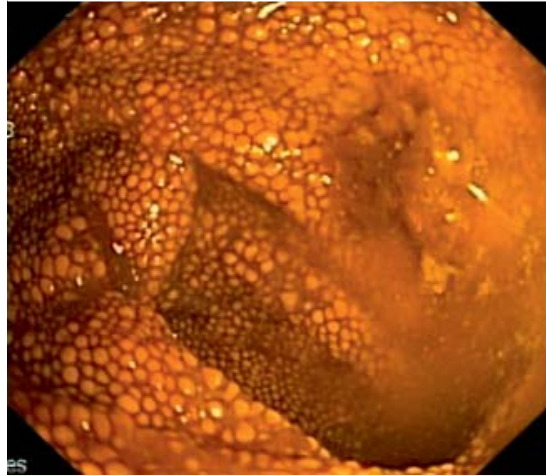

Fig. 1 Colonoscopy with ileoscopy in a 70-year-old man with a history of diarrhea and weight loss showing diffuse brown discoloration and white plaques affecting the mucosa in the terminal ileum.

A 70-year-old white man had been aware of mild memory loss, arthralgia, and altered bowel habits for 3 years prior to his referral. His gastrointestinal symptoms had worsened during the 2-month period preceding his referral, with diarrhea (five to six bowel movements of fatty stools per day) and a 4-kg weight loss. His laboratory workup, including thyroid function and human immunodeficiency virus (HIV) screening, was unremarkable. Colonoscopy showed normal colonic mucosa but ileoscopy revealed a diffuse brown appearance of the mucosa with scattered white plaques ( $\bullet$ Fig. $\mathbf{1})$.

Biopsy specimens taken from the terminal ileum revealed foamy macrophages in the lamina propria ( $\bullet$ Fig. $\mathbf{2 a}$ ) that stained positively with the periodic acid-Schiff $(\mathrm{PAS})$ reaction ( $\bullet$ Fig. $\mathbf{2 b}$ ). A negative acid-fast stain excluded Mycobacterium avium complex (MAC) infection. The duodenum appeared normal and biopsies showed no abnormalities. Treatment with trimethoprim-sulfamethoxazole for 1 year was instituted with prompt symptom resolution and $12-\mathrm{kg}$ weight gain after 6 months.

Whipple's disease is a rare chronic multisystem infection caused by Tropheryma whipplei. PAS-positive small-bowel biopsy specimens obtained during upper gastrointestinal endoscopy are usually diagnostic in the appropriate clinical setting, although polymerase chain reaction (PCR) tissue analysis is increasingly being used

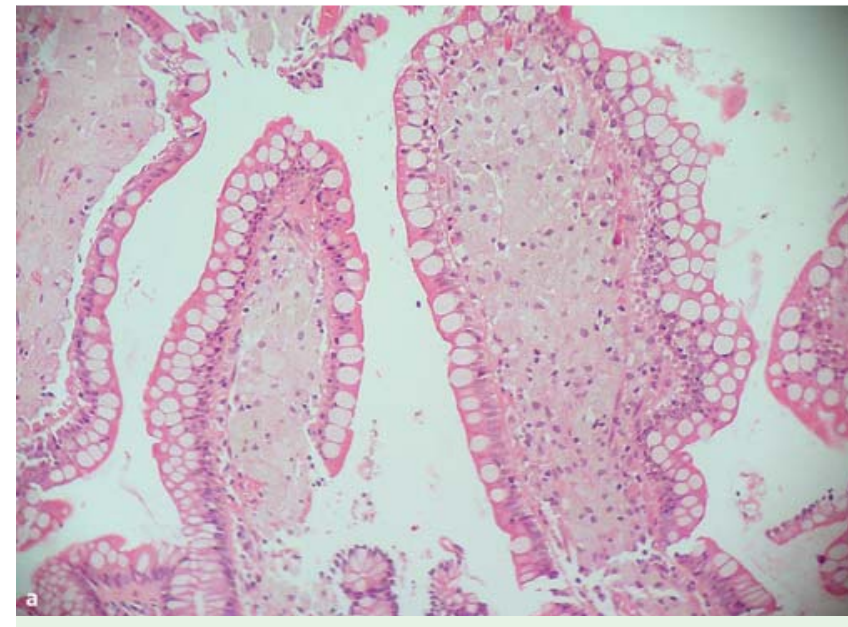

Fig. 2 Biopsy specimen taken from the terminal ileum stained with: a hematoxylin and eosin (H\&E; magnification $\times 10$ ) showing the ileal mucosa with massive infiltration of the lamina propria by macrophages that are packed with Whipple bacilli; $\mathbf{b}$ the periodic acid-Schiff (PAS) reaction (magnification $\times 40$ ) showing the macrophages of the lamina propria filled with red-stained PAS-

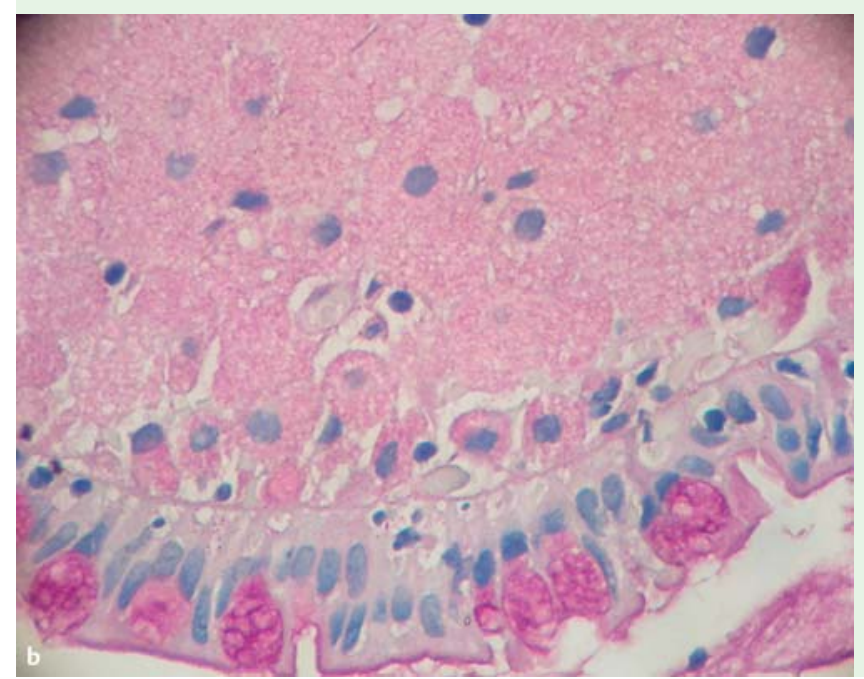
positive Whipple bacilli.

[1]. The reported small-bowel endoscopic features include edema and brown discoloration of the mucosa, erythematous spots, and subepithelial hemorrhages [2], which seem to disappear distally, usually in a continuous fashion [3]. Concomitant endoscopic disease of the terminal ileum has also been reported $[4,5]$ but to our knowledge this is the first description of endoscopic findings isolated to the terminal ileum and biopsy findings diagnostic of Whipple's disease.

Full imaging of the small bowel (including capsule endoscopy) was not performed due to institutional constraints but we found no other evidence of disease at upper or lower gastrointestinal endoscopy even after biopsy sampling of the duodenum and colon. In the future, colonoscopy with ileoscopy should be considered in the diagnostic workup of patients suspected of having Whipple's disease.

Endoscopy_UCTN_Code_CCL_1AD_2AJ

Competing interests: None

\section{J. Dinis Silva', V. Fernandes ${ }^{2}$, M. C. Alves ${ }^{3}$, J. Freitas $^{2}$}

${ }^{1}$ Department of Gastroenterology, Hospital do Espírito Santo de Évora EPE, Largo Senhor da Pobreza, Portugal

2 Department of Gastroenterology, Hospital Garcia de Orta EPE, Almada, Portugal

${ }^{3}$ Department of Histopathology, Laboratório Joaquim Chaves, Lisbon, Portugal 


\section{References}

1 Fenollar F, Puéchal X, Raoult D. Whipple's disease. N Engl J Med 2007; 356: 55-66

2 Monkemuller K, Fry LC, Von Arnim $U$ et al. Whipple's disease: an endoscopic and histologic study. Digestion 2008; 77: 161 - 165

3 Keane MG, Shariff M, Stocks J et al. Imaging of the small bowel by capsule endoscopy in Whipple's disease. Endoscopy 2009; 41: E139
4 Le Lan C, Dinasquet M, Salim B et al. Endoscopic and pathological aspect of small bowel and colonic involvement in Whipple's disease: a case report. Gastroenterol Clin Biol 2003; 27: 416-419

5 Cosme A, Ojeda E, Muñagorri AI et al. Diagnosis of Whipple's disease using molecular biology techniques. Rev Esp Enferm Dig 2011; 103: 213 - 217

\section{Bibliography}

Dol http://dx.doi.org/ 10.1055/s-0032-1325974 Endoscopy 2013; 45: E59-E60

(c) Georg Thieme Verlag KG Stuttgart · New York ISSN 0013-726X

\section{Corresponding author}

\section{J. Dinis Silva, MD}

Serviço de Gastrenterologia Hospital do Espírito Santo de Évora EPE Largo Senhor da Pobreza 7000-811 Évora

Portugal

Fax: +351-266-740117

jdinisilva@gmail.com 